\title{
¡Viva, viva, el rey de España!: Loas alegóricas al poder y a la monarquía en las "Plausibles fiestas reales"
}

\author{
Geannini Ruiz Ulloa \\ geaninniruiz@gmail.com \\ Universidad de Costa Rica, Costa Rica \\ https://orcid.org/0000-0003-3846-2430
}

Recibido: 14 de marzo 2018

Aceptado: 5 de junio 2018

\section{Resumen:}

Este artículo es una primera aproximación al estudio de la escritura dramática centroamericana en la colonia. En esta ocasión, se presentó un análisis textual de un conjunto de loas encontradas en la relación de fiestas "Plausibles fiestas reales" (1761). Dichos textos dramáticos forman parte de una narrativa barroca que busca exaltar la figura del rey y de las autoridades locales, teniendo como espacio de enunciación la provincia de Sonsonate, una alcaldía periférica en la cartografía del reino de Guatemala.

Palabras clave: literatura colonial, Centroamérica, teatro.

\section{¡Viva, viva, el rey de España!: Allegorical loas to power and monarchy In the "Plausibles fiestas reales"}

\section{Abstract:}

This article tries about the study of the Central American dramatic writing during the colony. In this occasion, I present an analysis of a set of loas found in the text "Plausibles fiestas reales" (1761), which are an account of special kind of celebration in the province of Sonsonate, a peripheral village in the cartography of the Kingdom of Guatemala. These dramatic texts are part of a baroque narrative seeking to exalt the figure of the king and local authorities.

Keys words: Colonial literature, Central American, theater.

\section{(c) (i) (2) (2)}

La Revista Estudios es editada por la Universidad de Costa Rica y se distribuye bajo una Licencia Creative Commons Atribución-NoComercial-Compartirlgual 3.0 Costa Rica. Para más información envíe un mensaje a 
Especial: Naturaleza amena y naturaleza agreste en las letras hispánicas

\section{INTRODUCCIÓN}

El teatro en la colonia jugó un papel importante dentro de las sociedades americanas. Su importación al continente tuvo un origen español, pero el arraigo en las prácticas culturales de los pueblos indígenas prehispánicos acompañó la reinterpretación de distintas tradiciones y géneros dramáticos. En una primera etapa de la conquista, las órdenes religiosas vieron en el teatro la manera de lograr transmitir los dogmas religiosos para los nuevos creyentes, sin embargo, conforme se asentaban las nuevas urbes americanas, el teatro se convirtió en un arte que formaba parte de la vida americana, por tanto, la presencia de compañías teatrales y la creación de teatros (edificios) formaron parte de la dinámica cultural de la colonia.

Dentro de ese marco, la sociedad colonial desarrolló un gusto por el fasto: las celebraciones y festividades civiles y religiosas eran parte de la visión de mundo influenciada por una lógica barroca peninsular. En ese sentido, los acontecimientos de la familia real se convirtieron en motivos de celebración para los pobladores americanos. Uno de los géneros discursivos en este tipo de prácticas fueron las relaciones de fiestas, las cuales tenían la finalidad de contar los sucesos acaecidos en un tiempo y espacio determinados, eran textos que pretendían narrar la realidad fáctica sobre una festividad o celebración; fueron populares en la España de los Trasmataras y Austrias. No obstante, los nobles que se trasladaron a América también incorporaron dicha costumbre.

En este trabajo, se parte de la relación de fiestas titulada Plausibles fiestas reales y obsequiosa demostración conque la muy leal Provincia de Sonsonate, proclamó en su villa de la Santísima Trinidad del Reino de Guatemala, el lunes 19 de enero de 1761. A su señor Católico Monarca y Señor Natural, (que Dios guarde) Don Carlos Tercero de Borbón ${ }^{1}$, dicha relación tiene características que la

\footnotetext{
${ }^{1}$ De ahora en adelante, citado como "Plausibles fiestas reales". 
Especial: Naturaleza amena y naturaleza agreste en las letras hispánicas hacen un texto excepcional en el marco de la literatura colonial centroamericana. Para afirmar esto compartimos las observaciones que brinda Sánchez Mora (2015) en su investigación: primero, es la única relación que incorpora una reproducción de textos dramáticos breves de manera completa; segundo, el lugar de enunciación es periférico al centro del reino de Guatemala, por lo que presenta características discursivas y retóricas diferentes y tercero, es una prueba documental y literaria que amplía las concepciones del canon literario colonial centroamericano que generalmente se ha considerado como reducido.

Los textos dramáticos de las "Plausibles fiestas" se componen de tres historias de moros y cristianos, una historia del Quijote, dos sainetes, tres entremeses y once loas. La diversidad de textos es una muestra representativa de la riqueza del teatro breve y de su importancia dentro de la lógica no solo de la representación, sino también del espectáculo teatral. En este análisis, nos limitaremos a presentar algunas de las características temáticas y discursivas de las loas, las cuales buscaron demostrar la lealtad y el apoyo hacia el monarca español, sin embargo, hay algunas características formales con las que planteamos una subdivisión: seis loas con un carácter más alegórico; dos loas que se centran en la presentación de Sonsonate como personaje y espacio; y tres que utilizan personajes populares (por ejemplo: capitán, soldado, ganapán).

Antes de comentar con nuestro análisis, señalaremos algunas precisiones sobre el contexto socio-histórico del reino de Guatemala y, particularmente, sobre la villa de Sonsonate, lugar en que se realizaron estas fiestas.

\section{CENTROAMÉRICA EN LA COLONIA}

Centroamérica tuvo un papel importante en los primeros años de la conquista española debido a su ubicación; ya que se convirtió en un lugar de paso para los conquistadores (Pérez- Brignoli 1985), sin embargo, no representó un

\section{(c) (1) (2)}

La Revista Estudios es editada por la Universidad de Costa Rica y se distribuye bajo una Licencia Creative Commons Atribución-NoComercial-CompartirIgual 3.0 Costa Rica. Para más información envíe un mensaje a 
Especial: Naturaleza amena y naturaleza agreste en las letras hispánicas espacio atractivo para comenzar con el proceso de colonización, pues no se encontraron yacimientos de oro y plata como en otras latitudes. El istmo se suscribía al Virreinato de Nueva España, pero debido a la extensión del territorio y para mejorar el control de la Corona, se creó otro órgano administrativo: la Audiencia de Guatemala ${ }^{2}$ en 1550 y, con ello, la creación de la ciudad de Santiago de los Caballeros como capitanía. La Audiencia velaría por las provincias de Guatemala (que incluía Chiapas), El Salvador, Honduras, Nicaragua y Costa Rica.

Las difíciles condiciones geográficas y la ausencia de minas convirtieron al reino de Guatemala en una región secundario dentro del mapa colonial. Las distintas provincias que la componían se caracterizaron por ser sociedades con una economía agraria. En el caso de El Salvador, los centros más importantes fueron las alcaldías de San Salvador y Sonsonate. A pesar de la cercanía que contó El Salvador en relación con la capitanía guatemalteca, hubo condiciones que permitieron diferenciar su composición social y cultural. Por ejemplo, se registró un porcentaje mayor de mestizaje que se favoreció debido al número de haciendas. Esto contribuyó a su vez a una disolución de los pueblos de indios: "las haciendas ahileras, al igual a como ocurrió en otras regiones de Hispanoamérica, provocaron la disolución de los pueblos de indios, tanto por sus crecientes necesidades de tierra como de mano de obra" (Solórzano Fonseca, 1982, p. 133). Lo anterior influyó significativamente en la región de Sonsonate.

La Villa de la Santísima Trinidad de Sonsonate fue fundada en el año de 1553 en la provincia de El Salvador. En su geografía, sobresale su cercanía a la costa pacífica, dos cadenas montañosas y la abundancia del recurso hídrico (afluentes y arroyos). Desde sus comienzos, se caracterizó como una sociedad agraria de subsistencia. Sin embargo, a finales del siglo XVII y comienzos del siglo XVIII, se desarrolló una expansión comercial en la producción del añil. En ese

\footnotetext{
${ }^{2}$ Previamente se había fundado la Audiencia de los confines (1542-1549).

La Revista Estudios es editada por la Universidad de Costa Rica y se distribuye bajo una Licencia Creative Commons Atribución-NoComercial-Compartirlgual 3.0 Costa Rica. Para más información envíe un mensaje a revistaestudios.eeg@ucr.ac.cr.
} 
Especial: Naturaleza amena y naturaleza agreste en las letras hispánicas sentido, las fiestas en honor a Carlos III surgieron dentro de cierto auge económico que trasmitía la ilusión de progreso.

\section{LAS LOAS EN LAS “PLAUSIBLES FIESTAS REALES”}

Las loas son un género teatral menor que busca introducir obras de mayor extensión, generalmente, guardan una relación temática con el texto que las sigue, aunque no necesariamente. Carlos Mata (2006) se refiere al carácter de preámbulo de la loa y señala como función principal captar la atención del público:

Es la pieza breve que precede al auto o a la comedia, una especie de preámbulo para captar la atención del público y conseguir su silencio y atención. Esta introducción al espectáculo está compuesta a veces en elogio de la ciudad en que se representa y del propio público, o bien, pondera la calidad de la obra que sigue y de la compañía, o bien, resume brevemente su argumento. En sus orígenes, la loa era recitada por un solo representante (de las cuarenta loas incluidas por Rojas Villandrando en El viaje entretenido, sólo tres son dialogadas), pero más adelante -como sucederá con otros géneros breves- se convirtió en un tipo de pieza dialogada (loa entremesada). Sus antecedentes pueden rastrearse en el "Prologus" del teatro latino e italiano y en el "Argumento" o "Introito" de las piezas españolas del XVI (por ejemplo, las de Torres Naharro) (Mata, p.153)

En el estudio de Correa y Cannon (1958) sobre la loa en Guatemala, se realiza una contextualización histórica sobre el género, en donde se señala la influencia de las celebraciones religiosas para su aparición. También del contacto con otros géneros dramáticos que convirtieron a la loa en un genero abierto

La loa es, pues, un género de fronteras culturales y si en un principio tuvo un origen gremial y se movió dentro de un ambiente estrictamente español, no hay duda que en su desarrollo posterior se desplazó hacia esta zona fronteriza cultural de entornos fluctuantes y movibles. Tal estado de cosas se fijó al parecer en el siglo XVIII y es el que actualmente prevalece tanto en México como en Guatemala (1958. p. 23)

\section{(C) $(00$}

La Revista Estudios es editada por la Universidad de Costa Rica y se distribuye bajo una Licencia Creative Commons Atribución-NoComercial-CompartirIgual 3.0 Costa Rica. Para más información envíe un mensaje a 
Especial: Naturaleza amena y naturaleza agreste en las letras hispánicas

\section{ANÁLISIS DE LAS PIEZAS}

\section{Loas alegóricas}

La literatura emblemática jugó un papel decisivo en la administración del gobierno, pues difundía la imagen de los monarcas a los súbditos de las colonias, ya que durante más de trescientos años de imperio los reyes de españoles nunca visitaron América. Por tanto, ante la ausencia de una imagen real, "la imagen ideal ocupa todo el espacio, difuminando las iconografías de los distintos monarcas y ofreciendo una única imagen, institucional y dinástica" (Mínguez, 1995, p. 18). En esa poética del poder (Mínguez 1995 citando a Tolosana 1991), las relaciones de fiestas participaron dentro de una lógica barroca que buscaba contar no solo cómo sucedió la fiesta, sino como debería haber sucedido, de ahí que Carmen Sáenz apunte que "existía una distancia entre lo que sucedió en realidad y lo que debería haber sucedido entre lo que se quería decir y lo que finalmente se entendió" (citado por Sánchez 2015).

La primera loa (que introduce a la comedia La mayor hazaña de Carlos $V$ de Diego Jiménez de Enciso) tiene como personajes al Sol y a la Luz, quienes disputan el cargo por presentar al nuevo monarca, según el que posea más méritos. Por un lado, el Sol argumenta que debe ser él quien presente al nuevo rey, pues de la misma manera que él da vida con sus rayos, el nuevo monarca es la luminaria de sus súbditos, los cuales deben poner su mirada en las virtudes que posee el rey.

Por otro lado, la Luz afirma, que al estar presente en la creación del mundo, tiene más importancia que el Sol, por tanto, debe ser ella quien represente la figura del rey. Sin embargo, después de la intervención de cada uno, concluyen que poseen casi los mismos méritos para representar al monarca español. La asociación del monarca con figuras solares forma parte de una iconografía que

\section{(c) (7) (-)}

La Revista Estudios es editada por la Universidad de Costa Rica y se distribuye bajo una Licencia Creative Commons Atribución-NoComercial-CompartirIgual 3.0 Costa Rica. Para más información envíe un mensaje a 
Especial: Naturaleza amena y naturaleza agreste en las letras hispánicas asemeja a los gobernantes con los astros. De hecho, desde nombre de Carlos, se busca enfatizar en su similitud con el Sol y la Luz. Veamos un ejemplo:

Luego en mi fe concreta

el CARO y el LUZ de la tarjeta:

o es que por sinalefa

se coma la o, porque entonces, deja

como puedes juntarlos,

¡El nombre propio del invicto Carlos!

Este juego de palabras sobre el origen del nombre Carlos - figurándose como raíces Caro y Luz - nos recuerda la tradición de las falsas etimologías de San Isidoro de Sevilla. Pero en ese caso, se reitera el carácter celestial y divino de Carlos III, quien ya desde su nombre hace una declaración de su poder y origen. Asimismo, la figura del rey se hiperboliza, se resaltan sus virtudes y dones para ser elegido como monarca; es una especie de apoteosis que encumbra al rey por encima de cualquier orden humano y divino. Por ejemplo, el siguiente fragmento proferido por el Sol

\author{
Monarca soberano \\ rasgo excelente de la diestra mano; \\ prospera tus estados, \\ los que viviere el sol, siglos contados; \\ y tus heroicas proezas, \\ nunca lleguen a ser muertas pavesas \\ domando tus blasones \\ la altivez de las bárbaras naciones, \\ que a tu brazo español, \\ infundiré mis rayos como sol.
}

Como señala Mínguez (2001), en la emblemática española se reúnen comparaciones en relación con la figura del sol, por ejemplo, su omnipresencia, su posición elevada (en los cielos) y su papel para el nutricio para la vida; son algunas de las características que trasladan a la figura del monarca.

\title{
(c) (i) (2)
}

La Revista Estudios es editada por la Universidad de Costa Rica y se distribuye bajo una Licencia Creative Commons Atribución-NoComercial-CompartirIgual 3.0 Costa Rica. Para más información envíe un mensaje a 
Especial: Naturaleza amena y naturaleza agreste en las letras hispánicas

En la loa, también la reina (Doña María Amelia de Sajonia) es alabada por las virtudes que representa y como pareja ideal que acompaña al soberano rey, generalmente, su figura se encuentra ligada con la Luna. En ese sentido, la dupla sol/luna se convierte en el símbolo usual para representar el matrimonio real.

En la segunda loa de este grupo, los personajes son siete imperios del mundo antiguo y moderno: Siria, Egipto, Constantinopla, Roma, Babilonia y España. Además, de los personajes del Genio y la Música, los cuales tienen la función de introducir la declaración de cada uno de las antiguos imperios. Con cada intervención de un personaje se va forman un altar según las letras del nuevo gobernante: CARLOS. Veamos un ejemplo,

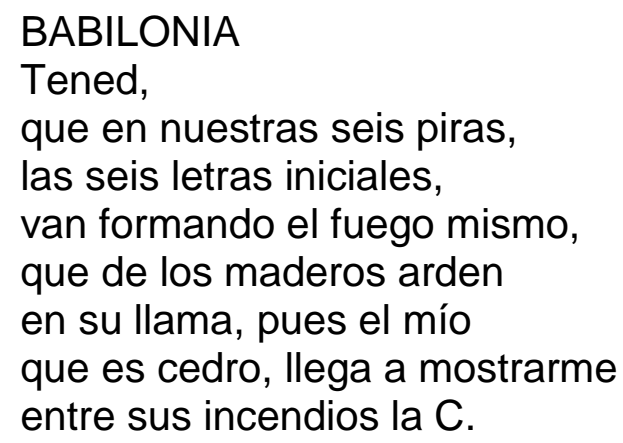

Con este altar que se efectúa en medio de la loa, los distintos imperios se rinden ante la figura del monarca español, quien aparece como vencedor y el más magnánimo de todos los gobernantes anteriormente conocidos. Además, por extensión, el imperio español se presenta como el más grande de todos los tiempos.

En la tercera loa, se desarrolla un coloquio entre la diosa Minerva y el dios Marte, pues como en la loa del Sol y la Luz, uno de ellos quiere merecer el honor de proclamar a Carlos III como nuevo monarca. Ante esa situación, Minerva sugiere encontrar un juez quien decida cuál de los dos posee más méritos, para ello, escogen a la Milicia.

\section{c) (i) (2)}

La Revista Estudios es editada por la Universidad de Costa Rica y se distribuye bajo una Licencia Creative Commons Atribución-NoComercial-Compartirlgual 3.0 Costa Rica. Para más información envíe un mensaje a 
Especial: Naturaleza amena y naturaleza agreste en las letras hispánicas

En la loa se recurre a la construcción de un epigrama con las intervenciones

de los dos dioses en el que se exaltan las virtudes de Carlos; composición poética común dentro de la narrativa barroca. Al final, la Milicia decide nombrar a los dos dioses en igual de condiciones para hacer la proclamación de Carlos III.

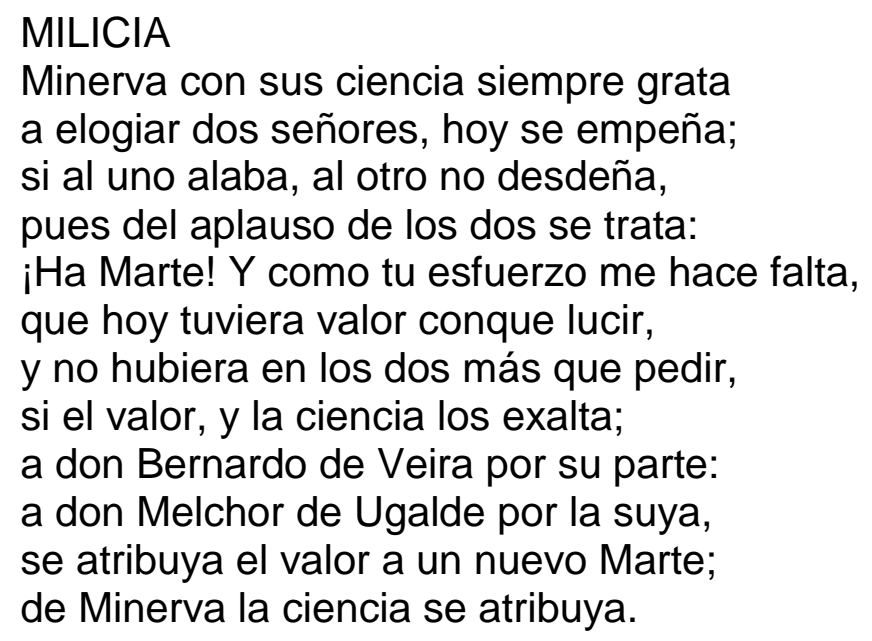

Asimismo, otro aspecto interesante no solo es exaltar la figura del rey por medio de los símbolos solares, sino también trasladar su autoridad a las figuras locales, es decir, aunque el rey no estuviera en el territorio americano, era por medio de los virreyes, alcaldes o gobernadores que se mantenía y respetaba el sistema monárquico. Por tanto, las autoridades locales de Sonsonate $\mathrm{y}$, especialmente, su alcalde Bernardo de Veyra es alabado por el autor de estas fiestas y, de la misma manera, cuenta con los atributos del monarca español.

Posteriormente, tenemos tres loas más que forman parte de este grupo y que tienen por personajes valores o virtudes que se presentan como personajes. Estas loas poseen mayor similitud con los autos sacramentales.

En la primera loa, los personajes son el Amor, la Justicia y la Música (que cumple un papel de introducir a ambos personajes). Tanto el Amor como la Justicia consideran que Carlos III es un rey con un corazón generoso y compasivo ante el prójimo, como un rey sabio y prudente para guiar al mejor término al

\section{(c) (i)(2)}

La Revista Estudios es editada por la Universidad de Costa Rica y se distribuye bajo una Licencia Creative Commons Atribución-NoComercial-CompartirIgual 3.0 Costa Rica. Para más información envíe un mensaje a 
Especial: Naturaleza amena y naturaleza agreste en las letras hispánicas

imperio. En la segunda loa, los personajes corresponden al Aplauso, la Fama y la Música. De hecho, son el Aplauso y la Fama, quienes emprenden un diálogo sobre sus tributos y trabajos, en esta oportunidad, se reúnen para alabar las glorias de Carlos III. En el tercer texto, los personajes son la Prudencia, la Justicia, la Fortaleza, la Templanza y la Música. Cada una de estas relaciona a Carlos III con su valor representado, al final cada una de ellas se rinde ante la grandeza del monarca.

\section{Sonsonate como personaje y espacio}

La segunda subtemática está compuesta de dos loas que buscan colocar a Sonsonate como una ciudad que demuestra su devoción hacia el régimen monárquico. No solo hubo un interés individual de ciertas figuras políticas - como el caso del alcalde - para la realización de las fiestas reales, sino también de carácter local, pues se tuvo una participación de todos los barrios y clases sociales tanto del programa festivo como de recursos económicos para su ejecución. Por tanto, la alcaldía de Sonsonate buscó figurar dentro del centro de poder más cercano - la ciudad de Santiago de los Caballeros - a partir de una ostentación de cierta manera moderada, ya que no contaba con los mismos recursos económicos, pero aun así inscribiéndose en una lógica barroca.

En la primera loa, se presentan los siguientes personajes: la Villa de Sonsonate, la Paz, la Fama, la Guerra, el Conocimiento y la Música. La Villa de Sonsonate como personaje comienza su intervención preguntando cuál es el sujeto que merece el cetro y corona que ella tiene para entregar. Después de esto, los otros personajes como la Paz, la Guerra y la Fama intentan demostrar los méritos que poseen para ser premiados por la Villa. Sin embargo, con la entrada en escena del Conocimiento, la atención se centra en la figura de Carlos III como monarca que supera cualquier mérito humano o divino.

\section{(c) (i) (2)}

La Revista Estudios es editada por la Universidad de Costa Rica y se distribuye bajo una Licencia Creative Commons Atribución-NoComercial-CompartirIgual 3.0 Costa Rica. Para más información envíe un mensaje a revistaestudios.eeg@ucr.ac.cr. 


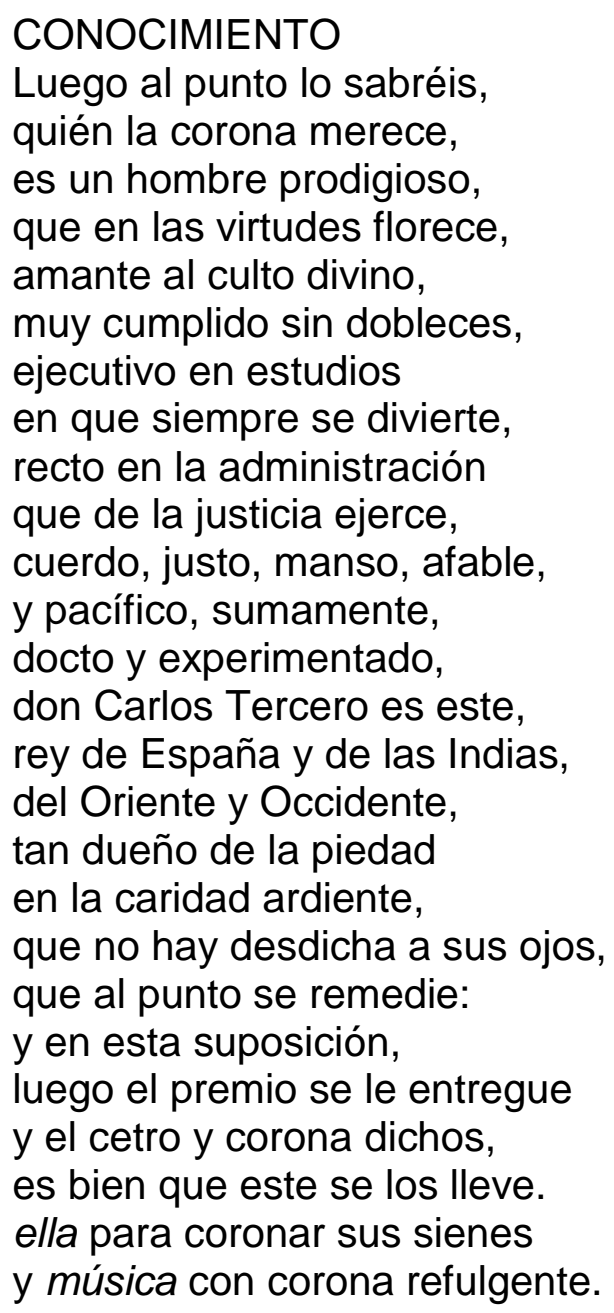

De manera parecida a la subtemática anterior, se subraya la exaltación hacia el monarca español. No obstante, resulta muy interesante el protagonismo que toma la Villa de Sonsonate como personaje, pues podría suponerse un deseo de llamar la atención de las autoridades de la capitanía, ya que El Salvador a pesar de encontrarse cerca del centro cultural recibe un papel secundario y periférico. De hecho, el posterior éxito añilero que tendrá la provincia parece anunciarse con esta relación de fiestas, pues en ningún otro momento - hasta donde se tiene conocimiento - se ha conservado una relación impresa.

\section{(c) (i) (2)}

La Revista Estudios es editada por la Universidad de Costa Rica y se distribuye bajo una Licencia Creative Commons Atribución-NoComercial-CompartirIgual 3.0 Costa Rica. Para más información envíe un mensaje a 
Especial: Naturaleza amena y naturaleza agreste en las letras hispánicas

Al final de la loa, los personajes reconocen que solo Carlos IIII es el indicado para gobernar, por lo que la Villa ofrece el cetro y la corona. Posteriormente, los demás personajes lanzan alabanzas que demuestran la sumisión y lealtad de sus pobladores

\title{
FAMA
}

Reinad en hora buena, que de placeres esta villa llena os aplaude gozosa, celebrando su fuerte venturosa con la nueva ceniza, que el pájaro inmortal de si eterniza.

En la segunda loa, solo tenemos un personaje: la provincia de Sonsonate. Esta composición es bastante corta, en ella de nuevo se manifiesta como todos los habitantes participan en la celebración de la fiesta.

\author{
PROVINCIA \\ La lealtad de esta provincia \\ amado Carlos Tercero, \\ (ya que os dan ese renombre \\ siendo en las almas primero) \\ vuelvo a deciros, señor, \\ que todo aqueste hemisferio, \\ no descansa en elogiarnos \\ con el más rendido esmero, \\ en adoración te aclama \\ reverente, amante, ciego, \\ que en los nobles corazones, \\ suene el amor y el respeto, \\ hasta en los indios ajenos, \\ resalta la voluntad \\ de verte en el solio regio.
}

\section{(C) $(0)$}

La Revista Estudios es editada por la Universidad de Costa Rica y se distribuye bajo una Licencia Creative Commons Atribución-NoComercial-CompartirIgual 3.0 Costa Rica. Para más información envíe un mensaje a 
Especial: Naturaleza amena y naturaleza agreste en las letras hispánicas

\title{
Loas con personajes populares
}

Este último apartado se caracteriza por tres textos dramáticos que poseen personajes de carácter popular. En la primera loa, los personajes son un capitán y un ministro real. La pieza comienza con el agradecimiento del marinero a Dios por haberlo traído bien a tierra firme. El marinero llega al puerto de Acajutla donde lo recibe el ministro, quien le pregunta de dónde viene, y éste le cuenta una serie de padecimientos que atravesó con su tripulación antes de llegar a tierra. Ante eso, el ministro le dice que deje la tristeza para otro momento, ya que en este momento en la villa se están realizando las fiestas en honor a Carlos III.

\author{
MINISTRO \\ Siento de tu fortuna tal vaivén; \\ pero amigo, te doy el parabién; \\ y de la aclamación \\ de nuestro Carlos Tercero de Borbón, \\ por tierra nuestros cuellos, \\ sobre mi cabeza colocaré sus sellos \\ y a toda diligencia, \\ le juraré esta villa la obediencia; \\ y ordenaremos leales \\ en tan plausible gozo, fiestas reales; \\ son que quede ninguno \\ de sus pueblos, que no venga uno a uno \\ con comedias, sainetes, \\ encamisada, bailes diferentes, \\ con músicas a coros, \\ carros, marchas, juegos, toros, \\ y el día de la jura; \\ función de iglesia encomendada al cura \\ de gracias en la acción, \\ misa solemne y publica oración.
}

Posteriormente, la segunda loa de este grupo tiene como personaje a un capitán, quien en toda su intervención invita a los habitantes de Sonsonate a 
Especial: Naturaleza amena y naturaleza agreste en las letras hispánicas aclamar la figura de Carlos III como monarca de manera similar que el ministro real.

La tercera loa posee como personajes a un soldado y un ganapán. El soldado carga una escopeta con que la realiza un disparo en honor a la jura de Carlos III, luego entra en escena el ganapán. Se desarrolla un diálogo entre ambos, pues el soldado tiene hambre, por lo que le pide al ganapán alguna vianda pero este solo le puede ofrecer sus escritos. En la respuesta del soldado, éste crítica las letras, ya que el mejor oficio que puede tener un ser humano es el de la milicia. A lo que el ganapán contesta:

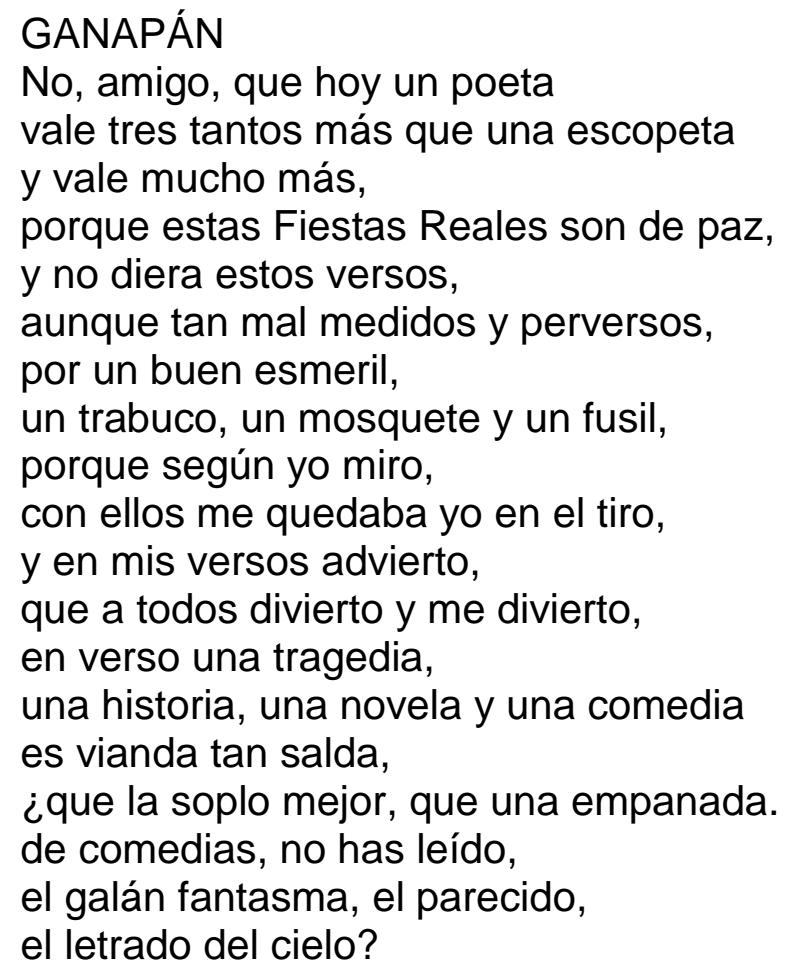

El ganapán le explica que también se puede conseguir fama por las letras y que esta perdura más que las balas de una escopeta. Es interesante la oposición que se plantea entre las letras y las armas, pues evidentemente recuerda a la elaborada por el Quijote. En el fragmento anterior, el personaje del ganapán hace 
ISSN 1659-3316

Diciembre 2018

Especial: Naturaleza amena y naturaleza agreste en las letras hispánicas una mención hacia las fiestas y resulta interesante la reflexión que elabora sobre el valor de la palabra para la imaginación y la diversión. El final del coloquio termina con una exaltación de ambos personajes sobre el valor y la sabiduría de Carlos III.

\section{CONCLUSIÓN}

Este primer acercamiento buscó agrupar las loas del texto "Plausibles fiestas reales" a partir de subtemáticas relacionadas con la exaltación del poder y del sistema monárquico. Esta diversidad de motivos y formas en el teatro breve demuestra la hibridez textual (Sancho 2016) que acompañó la demanda de la representación teatral en la colonia. 
Especial: Naturaleza amena y naturaleza agreste en las letras hispánicas

\section{BIBLIOGRAFÍA}

Castellón, J. R. (2013). Vida, alimentación y fiestas en los territorios del Reino de Guatemala. San Salvador, Sonsonante, siglo XVII. Tesis para optar por el título de doctor.: Universidad de Sevilla.

Correa, G. y. (1958). La loa en Guatemala. New Orleans: Middle American Research Institute.

Mata, C. (2006). Panorama del teatro breve español. Mapocho. Revista de humanidades , 143-164.

Mínguez, V. (1995). Los reyes distantes. Imágenes del poder en el México virreinal . Castelló de la Plana: Publications de la Universitar Jaume I. D. L .

Mínguez, V. (2001). Los reyes solares iconografía astral de la monarquía hispánica . Castellón de la Plana: Publicaciones de la Universitat Jaume I.

Molina, J. A. (2003). Pintando el mundo de azul. El auge añilero y el mercado centroamericano 1750-1810. CONCULTURA.

Pérez-Brignoli, H. (1985). Breve historia de Centroamerica. México: Alianza.

Sánchez, A. (2015). La literatura y fiesta en los márgenes del Imperio: las relaciones de fiesta en Centroamerica, s. XVII a XIX. Tesis para optar por el grado de doctor. : Universidad de Sevilla .

Sancho, L. (2016). Teatro breve en la provincia de Costa Rica. Tres piezas de Joaquín de Oreamuno y Muñoz de la Trinidad. New York: Instituto de Estudios Auriseculares.

\section{(c) (i) (2)}

La Revista Estudios es editada por la Universidad de Costa Rica y se distribuye bajo una Licencia Creative Commons Atribución-NoComercial-CompartirIgual 3.0 Costa Rica. Para más información envíe un mensaje a 